\title{
Os diálogos entre preceptor e residente no contexto da Residência Pedagógica: reflexões em prol de uma construção de identidade docente
}

\author{
Edvaldo Santos de Lira \\ Secretaria da Educação, Ciência e Tecnologia do Estado da Paraíba \\ edvaldolira17@hotmail.com \\ Betânia Passos Medrado \\ Universidade Federal da Paraíba \\ betamedrado@gmail.com \\ Walison Paulino de Araújo Costa \\ Universidade Federal da Paraíba \\ walliecoast@yahoo.com.br
}

\section{Resumo}

O Programa Residência Pedagógica (RP) objetiva inserir o licenciando no ambiente escolar para o exercício docente. Na vigência do primeiro edital, o Núcleo Letras Espanhol/Inglês do Departamento de Letras Estrangeiras da UFPB formou um coletivo com 27 residentes, alocados em três escolas integrais, nos municípios de João pessoa e Bayeux. As atividades dos residentes dividiram-se em: ambientação, regência, observação, reuniões formativas, além da elaboração de um plano de intervenção. Em cada escola, os residentes foram acompanhados por um preceptor, responsável por supervisionar todo o trabalho desenvolvido. Considerando esse cenário formativo, objetivamos, neste trabalho, refletir sobre a construção da identidade docente com base nos diálogos de um residente com sua preceptora. Nosso corpus é constituído de relatos reflexivos, escritos pelo residente e analisados sob um viés qualitativo-interpretativista. Este trabalho apoia-se na concepção sobre identidade (HALL, 2005; BAUMAN, 2005; 2014[2001]), identidade e formação docente (TARDIF, 2002; OLIVEIRA; BOER, 2018; REICHMANN, 2015; 2013) e observação no contexto de formação inicial (BIAZI, GIMENEZ, STUTZ, 2011). O resultado da nossa análise evidenciou que os diálogos entre preceptora e residente contribuíram significativamente para a 
construção da identidade profissional do docente em formação, numa perspectiva crítico-reflexiva.

Palavras-chave: Residência Pedagógica. Formação inicial. Identidade docente.

\section{Abstract}

The Pedagogical Residency Program (PR) aims at inserting the undergraduate student into the school for teaching practice. During the first call for proposals, the Spanish/English Language Group from the Department of Foreign Languages at UFPB constituted a collective with 27 residents. They were allocated in three fulltime schools in the cities of João Pessoa and Bayeux. The residents' activities were divided into setting, observing, teaching, input meetings, besides developing an intervention plan. In each school, a preceptor accompanied the residents, and he/she supervised all the work developed. Considering this formative scenario, we aim, in this paper, at reflecting on the construction of the teacher identity from the dialogue between a resident and his preceptor. Our corpus comprises reflective reports, written by the resident, and analyzed under a qualitative-interpretative perspective. This paper relies on the conception of identity (HALL, 2005; BAUMAN, 2005; 2014 [2001]), identity and teachers' formation (TARDIF, 2002; OLIVEIRA; BOER, 2018; REICHMANN, 2015; 2013) and observation in initial teacher education context (BIAZI, GIMENEZ, STUTZ, 2011). The result of our analysis showed that the dialogues between preceptor and resident added to the construction of the pre-service teacher professional identity, from a criticalreflexive perspective.

Keywords: Pedagogical Residence. Initial teacher education. Teacher identity.

\section{Para início de conversa: o Programa de Residência Pedagógica}

Ao definir Residência Pedagógica (RP), o edital Capes n. 06/2018 asserta que ela é "uma atividade de formação realizada por um discente regularmente matriculado em um curso de licenciatura e desenvolvida numa escola pública de educação básica, denominada escola-campo" (BRASIL, 2018, p. 1, grifos nossos). Para uma conceitualização inicial e mais geral da RP, os três termos destacados, a nosso ver, são muito relevantes. A Residência é um programa de iniciação à docência que tem como agente desenvolvedor das atividades o estudante de licenciatura, e o lócus desse desenvolvimento é a escola de Educação Básica.

Desse modo, o Programa tem como finalidade inserir o licenciando no contexto escolar para que ele experiencie a prática docente. De acordo 
com o edital supracitado, as atividades desenvolvidas na RP ainda têm como objetivo proporcionar o exercício da relação entre teoria e prática docente; fortalecer o diálogo entre as Instituições de Ensino Superior (IES) e as escolas de Educação Básica, sobretudo escolas públicas; e promover a adequação das atividades sob a ótica da Base Nacional Comum Curricular (BRASIL, 2018).

Durante a vigência do primeiro edital da RP - agosto de 2018 a janeiro de 2020 -, no Núcleo Letras Espanhol-Inglês do Departamento de Letras Estrangeiras Modernas (DLEM), na Universidade Federal da Paraíba (UFPB), as atividades foram organizadas em fases de ambientação, regência, observação e elaboração de um plano de intervenção, ${ }^{1}$ além de reuniões formativas. O referido Núcleo formou-se com um coletivo de 27 alunos residentes, que compuseram outros três coletivos alocados em três diferentes escolas nos municípios de João Pessoa e Bayeux. Em cada instituição escolar, os residentes foram assistidos por um preceptor, que acompanhava todo o trabalho dos residentes nas atividades pedagógicas dentro e fora de sala de aula. Durante todo o processo de criação e progressão das atividades, eles também foram orientados pelo professor e pelas professoras orientadoras do Núcleo.

A carga horária total do Programa compreendeu 440 horas, divididas da seguinte maneira: 220 horas voltadas à imersão do residente na escola-campo; 100 horas de regência; 70 horas de reuniões de formação e orientação na IES; 30 horas para a participação em eventos acadêmicos; e 20 horas para elaboração de relatos e relatórios (MEDRADO; COSTA, 2020).

As reuniões na IES aconteciam, majoritariamente, de forma quinzenal com todo o Núcleo. Nelas, eram discutidos textos teóricos concernentes à formação de professores; documentos oficiais regulatórios para a Educação Básica; socialização das atividades entre os residentes, preceptores e orientadores, além de outras temáticas que eram avaliadas como pertinentes para o espaço da Residência Pedagógica. Reuniões com

\footnotetext{
${ }^{1}$ De acordo com o edital Capes n. 06/2018, cada residente precisava desenvolver pelo menos um plano de intervenção na escola onde ele estava inserido. Não existia um modelo específico; tratava-se de uma atividade realizada no espaço escolar pelo residente ao longo dos processos vividos no Programa.
} 
os coletivos alocados na escola também sucediam quinzenalmente e tinham caráter formativo. Essas reuniões funcionavam como um espaço para socialização e resolução de demandas recorrentes, das quais participavam os professores orientadores e os residentes que desenvolviam as ações em cada uma das escolas.

No que concerne ao momento inicial de imersão na escola, os residentes não regeram aulas, mas observaram, escreveram, dialogaram com alunos, professores, funcionários, entre eles, sobretudo, com o preceptor. Durante todo o Programa, percebemos que o diálogo construído entre residentes e preceptores foi constante e necessário para 0 planejamento e a execução das atividades. Nesse sentido, este estudo objetiva, com base na análise de relatos reflexivos escritos por um residente, responder como a primeira versão da Residência Pedagógica, lançada nacionalmente para a formação de professores, oportunizou espaços de construção identitária docente desse residente, entre outras vias, substancialmente, pela vivência de processos dialógicos com a preceptoria.

Diante do exposto, propomos, neste artigo, analisar oito relatos reflexivos produzidos por um residente, participante do Núcleo supracitado, com a finalidade de evidenciar como sua identidade docente foi sendo construída discursiva e dialogicamente. Para tanto, retomamos, na primeira seção, alguns estudos sobre identidade (HALL, 2005; BAUMAN, 2005; 2014[2001]), e identidade e formação docente (TARDIF, 2002; OLIVEIRA; BOER, 2018; REICHMANN, 2015; 2013, dentre outros), além de escritos relacionados à tarefa de observação no contexto de formação inicial (BIAZI; GIMENEZ; STUTZ; 2011). Na seção seguinte, apresentamos os procedimentos metodológicos da pesquisa, para, finalmente, discutirmos os excertos selecionados, relacionando, de maneira situada, as temáticas evidenciadas nos relatos com os estudos teóricos sobre identidade docente. Finalmente, em uma última seção, trazemos algumas considerações que dizem respeito à construção identitária do residente, produtor dos relatos, e o papel do diálogo que ele manteve com sua preceptora ao longo da Residência Pedagógica. 


\section{Discutindo identidades docentes em construção}

De acordo com o Cambridge Dictionary, ${ }^{2}$ o termo identidade revela quem a pessoa é, as qualidades que a tornam diferente de outros sujeitos. Ao dialogar com as várias definições do termo construídas ao longo da história, Hall (2005) apresenta três concepções de identidade vinculadas ao sujeito no Iluminismo, ao sujeito sociológico e ao sujeito pós-moderno.

Panoramicamente, podemos dizer que a primeira concepção está atrelada à identidade do sujeito como sendo única, central e imutável. Concebe-se identidade aqui, portanto, como uma expressão de humanidade que permeia a noção de univocidade do início ao fim de sua vida subjetiva, numa primeira instância. Numa segunda instância, a centralidade suscita uma ideia de razão e consciência totalizadora desse eu individual, nuclear, interno e, por conseguinte, imanentista (herdada da virada antropocêntrica), características que trazem implicações para uma terceira instância, ou seja, a imutabilidade identitária. Incisiva e derradeiramente, podemos dizer que, nessa concepção, identidade é vista como fixa, essencial e imutável.

Por sua vez, a segunda concepção destaca identidade como algo que permeia o exterior e o interior do sujeito. Dessa forma, entendemos que há uma espécie de prolongamento da primeira concepção, pois o que se acrescenta aqui é a interatividade com o mundo fora de si, embora, ainda, na perspectiva subjetiva, o eu mais autêntico, real seja o nuclear, o inato. Ademais, vale dizer que, em função das reconfigurações em termos de complexidade do contexto moderno, iniciou-se certa contestação ao caráter autossuficiente desse eu individual, apontando para um entrelugar que poderia ser ocupado por esse sujeito sob uma ótica dual - decorrência dos mundos pessoal e público. Assim, passou-se a contemplar também sua exteriorização, estabelecendo-se a noção de sujeito individual que também se relaciona, se constitui, consequentemente, a partir da interação com seu meio social.

\footnotetext{
${ }^{2}$ Identity In: Cambridge Dictionary. Disponível em: 〈https://dictionary.cambridge.org/pt/dicionario/ingles/identity>. Acesso em: 10 maio 2020.
} 
Finalmente, a terceira concepção de identidade, e a que mais se aproxima da discussão proposta neste trabalho, está relacionada ao sujeito pós-moderno, fragmentado. $\mathrm{O}$ autor define essa ideia de identidade como sendo fluida, ou seja, como não essencial ou permanente, uma vez que ela se torna uma celebração comovente, continuamente formada e transformada em relação à maneira como o sujeito é representado ou desafiado nos sistemas culturais de seu entorno, nos quais está/é "inscrito".

Nesse sentido, Hall (2005) discute que não há identidade fixa. Pelo contrário, diante da multiplicidade dos sistemas de significado e representação cultural, as pessoas são confrontadas por identidades plurais e mutáveis com as quais podem/poderiam identificar-se, pelo menos temporariamente (HALL, 2005). Ainda, no que diz respeito ao conceito de identidade, em um sentido mais abrangente e, a nosso ver, também alinhado aos estudos culturais de Hall (2005), Iza et al. (2014) definem o termo como o processo de construção social de um sujeito. Assim, imerso na sociedade, esse sujeito se (re)constrói contínua e dinamicamente com base nas experiências particularmente vivenciadas nesse contexto.

A concepção de fluidez em Hall (2005) dialoga com os estudos de Bauman (2014 [2001]) sobre a condição sempre dialógica e provisória da identidade humana. O moderno líquido (BAUMAN, 2005; 2014[2001]) aponta para o fato de que é sempre um esforço de vigilância nos percebermos imersos nos fluidos constantes, inevitáveis e moventes da vida social. Além disso, como nos diz Bauman, esses fluidos são, na maioria das vezes, à nossa revelia, produzidos e lançados por outrem a nossa volta.

Quando pensamos também na fluidez inerente à construção de uma identidade docente e de todos os processos formativos que envolvem essa identidade, o Programa de Residência Pedagógica apresenta-se como potencial indubitável para funcionar como outra possível via, ${ }^{3}$ por meio da qual os residentes possam perceber-se no processo de desenvolvimento profissional. Não foram poucos os conflitos, as decisões tomadas, os

\footnotetext{
${ }^{3} \mathrm{E}$, quiçá, com potencial ainda mais forte que outros segmentos formativos ligados à própria licenciatura, tendo em vista os processos de imersão no espaço escolar, oportunizados tanto pela duração de tempo mais prolongada quanto pelas consequentes relações dialógicas com a preceptoria e com os demais atores envolvidos, advindas dessa imersão.
} 
redirecionamentos feitos. Isso, de fato, demandou, pelo que percebemos no nosso Núcleo, um novo olhar para como cada um dos residentes estava enfrentando as situações, lidando com os alunos e com seus respectivos preceptores.

A esse respeito, estudos vêm sendo realizados, no campo da formação de professores, sobre identidade docente (OLIVEIRA; BOER, 2018; REICHMANN, 2015; 2013, para citar alguns) e versam sobre diferentes aspectos da construção identitária do professor em formação inicial.

Araújo et al. (2018), por exemplo, destacam que a construção de uma identidade docente não se dá em momento específico; pelo contrário, o professor desenvolve sua identidade profissional durante uma vida inteira. Esse processo identitário, que implica (des)continuidades, perpassa suas escolhas, sua formação inicial e toda sua trajetória. Nessa perspectiva, Gonçalves (2016) argumenta também que a identidade docente "é (re)construída a todo momento conforme as situações que o trabalhador vive. Ela é feita de saltos, rupturas e também de continuidades" (GONÇALVES, 2016, p. 15).

Nesse sentido, Garcia et al. (2005) entendem que a categoria está relacionada às posições o dispostas aos sujeitos por meio dos diversos discursos e agentes sociais. Além disso, os autores ainda chamam atenção para um conjunto de representações em circulação relativas "aos modos de ser e agir dos professores e professoras no exercício de suas funções em instituições educacionais, mais ou menos complexas e burocráticas" (GARCIA; HYPOLITO; VIEIRA, 2005, p. 48).

Ainda, ao tratarmos das possíveis definições do termo, os autores ponderam sobre identidade profissional docente como uma construção social assinalada por diversos fatores que se comunicam e interagem entre si. Garcia et al. (2005) denunciam que essa definição resulta

[...] numa série de representações que os docentes fazem de si mesmos $e$ de suas funções, estabelecendo, consciente $e$ inconscientemente, negociações das quais certamente fazem parte suas histórias de vida, suas condições concretas de trabalho, o imaginário recorrente acerca dessa profissão certamente marcado pela gênese e desenvolvimento histórico da função docente -, e os discursos que circulam no mundo social 
Os diálogos entre preceptor e residente...

e cultural acerca dos docentes e da escola (GARCIA; HYPOLITO; VIEIRA, 2005, p. 54).

Entendemos que o contexto da RP concede espaço para o professor em formação, de modo que ele possa desenvolver sua identidade profissional. Por meio desse espaço formativo, muitos estudantes que não têm prática docente se veem pela primeira vez em uma sala de aula como professor residente. Como mencionado anteriormente, entre outros objetivos, a RP permite que o licenciando possa perceber como a teoria dialoga com a prática e, sob esse viés, atesta que a formação teórica necessita de formação prática (TARDIF, 2002). Aliás, de acordo com Tardif (2002, p. 57), "acontece raramente que a formação teórica não tenha de ser completada com uma formação prática, isto é, uma experiência direta do trabalho". Desse modo, a Residência apresenta-se como espaço que promove esse contato, o que oportuniza não apenas o surgimento, em muitos casos, mas também o desenvolvimento da identidade profissional.

No que diz respeito também às concepções de identidade docente e de trabalho, Tardif (2002) destaca que a aprendizagem estabelecida com base em uma relação entre um aprendiz e um trabalhador experiente é comum nas práticas desenvolvidas em magistério. Todavia, é pertinente destacar que a experiência não deve ser tomada como fator que posiciona $o$ professor experiente como hierarquicamente superior. Entendemos que, em um ambiente de trabalho, todas as experiências são imprescindíveis para a construção e a reconstrução dos processos identitários.

A RP permite que o residente esteja imerso mais profundamente nessa cultura escolar, em que se (re)constrói como docente. As atividades estabelecidas concedem ao licenciando uma experiência mais ampla dos mais diversos aspectos no campo de sua futura prática. Além disso, o preceptor é visto como um orientador no processo de formação, uma vez que ele não é apresentado como um modelo que o residente necessita observar e copiar. Pelo contrário, ele orienta, dialoga e cresce junto com os residentes e os alunos. É uma constante troca de experiências e aprendizados, permitindo o (re)fazer-se profissional.

Recorremos ainda a Costa e Fontoura (2015), que, ao discutirem sobre o período inicial da docência, destacam que

[...] não apenas significa um momento de aprendizagem do ofício de ensinar, em função do contato com alunos. Significa, também, 
um importante momento de socialização profissional, da inserção na cultura escolar, da interiorização das normas, valores institucionais, preceitos, comportamentos, procedimentos. Algo que se efetiva no local de trabalho do professor e, por acontecer na escola, propicia o desenvolvimento de competências profissionais (COSTA E FONTOURA, 2015, p. 163).

Esse primeiro contato com a docência, com o campo da prática, é também o momento em que professores podem refletir sobre seus papéis como agentes transformadores, suas crenças, objetivos e posicionamentos. É o lugar onde podem ver o que funciona e o que não funciona. É o lugar em que estão constantemente aprendendo, principalmente quando suas propostas não dão certo. E essas vivências são de extrema importância para uma reflexão sobre a prática e, por conseguinte, para a construção identitária profissional.

No que diz respeito, mais uma vez, à fase de observação do contexto escolar, Biazi et al. (2011, p. 71) lembram a observação de aulas "como um espaço necessário para o cultivo do saber partilhado e para a construção de si próprio e dos outros em uma reflexão permanente com o que nos rodeia e com as nossas questões sócio-históricas”. Nesse sentido, as observações e os diálogos entre residente e preceptor marcam o processo de partilha. Dentre as inúmeras contribuições desses diálogos e experiências compartilhadas, destacamos o processo de observação como de suma notabilidade para a aprendizagem de novos métodos e abordagens, para a construção de si como professor e para a reflexão sobre questões tais como: "o que eu faria se essa situação acontecesse comigo?", por exemplo.

Finalmente, o trabalho desenvolvido pelo preceptor e pelo residente é caracterizado pela colaboração e pela parceria. Residentes, juntamente com o preceptor, formam um só coletivo que compartilha ideias, (in)certezas, questionamentos. Esse trabalho em parceria é peça-chave para a realização de atividades no âmbito escolar e para as etapas de (re)construção da identidade docente. Veremos esses aspectos com mais detalhes nas próximas seções. 


\section{Procedimentos metodológicos}

Ao longo de todo o desenvolvimento das atividades no Núcleo Letras Espanhol-Inglês, os residentes foram engajados em produção de textos - relatórios, relatos reflexivos e comentários críticos ${ }^{4}$ - não apenas como registro das atividades, mas, principalmente, como forma de provocar o grupo para uma leitura crítica sobre o trabalho docente e as re/construções de representações acerca das atividades de ensino de línguas na Educação Básica.

No que concerne aos relatos reflexivos, todos os residentes alocados no Núcleo supracitado escreviam um relato a cada visita feita à escola-campo. Nesses relatos, eles textualizam suas experiências naquele dia específico: as decisões, os conflitos, os impedimentos, as emoções - as várias dimensões de sua atividade docente.

No que diz respeito ao residente colaborador da pesquisa, cabe mencionar que, durante sua participação no Programa, ele produziu quarenta relatos reflexivos, nove comentários críticos, além de quatro relatórios, um plano de atividades e um plano de intervenção.

Tabela 1. Textos produzidos pelo residente no âmbito da RP

\begin{tabular}{lllll}
\hline $\begin{array}{l}\text { Relatos } \\
\text { reflexivos }\end{array}$ & $\begin{array}{l}\text { Comentários } \\
\text { críticos }\end{array}$ & Relatórios & $\begin{array}{l}\text { Planos de } \\
\text { atividade }\end{array}$ & $\begin{array}{l}\text { Planos de } \\
\text { intervenção }\end{array}$ \\
\hline 40 & 09 & 04 & 01 & 01 \\
\hline
\end{tabular}

Fonte: elaboração dos autores

Como mencionado previamente, este estudo objetiva responder como a Residência Pedagógica se configurou como espaço para a construção da identidade docente de um residente por meio dos diálogos estabelecidos entre ele e sua preceptora. Para tanto, selecionamos oito relatos dentre os quarenta escritos pelo residente durante sua participação na RP. A seleção dos oito relatos se deu em virtude de eles se caracterizarem emblematicamente ilustrativos dessa relação dialógica do

\footnotetext{
${ }^{4}$ Os comentários críticos eram solicitados após a leitura de textos teóricos que versavam sobre formação de professores, ensino de língua estrangeira, metodologias, etc.
} 
residente com a preceptoria. Além disso, dado o total de quarenta relatos produzidos, consideramos esse número compatível com o objetivo delineado na introdução.

Os textos são analisados sob um viés qualitativo-interpretativista. De acordo com Gerhardt e Silveira (2009), a pesquisa qualitativa tem como princípio o aprofundamento da compreensão de grupos sociais. Desse modo, não há uma preocupação direta com uma quantidade numérica, mas, sim, com a "compreensão e explicação da dinâmica das relações sociais" (GERHARDT; SILVEIRA, 2009, p. 31).

Ao discutir a formação de professores, Nóvoa (2009) evidencia que registrar suas vivências pessoais e profissionais se configura como essencial para uma reflexão mais consciente do seu trabalho e de sua identidade docente. Ainda no que diz respeito à análise de textos, MunizOliveira (2016) asserta que "os conflitos vividos, os impedimentos do agir, as múltiplas tarefas atribuídas ao docente podem se manifestar em textos nos quais o professor comenta/descreve/aborda o seu próprio trabalho (MUNIZ-OLIVEIRA, 2016, p. 80).

Por conseguinte, vemos a análise de relatos como ferramenta para uma nova compreensão sobre as representações do residente sobre seu próprio trabalho. É, a nosso ver, uma possibilidade de visualizar mais amplamente as dimensões de sua atividade e sua construção identitária docente, compreendendo os conflitos, o trabalho coletivo, as perspectivas que cada um coloca sobre sua atividade, entre vários outros aspectos que constituem o trabalho docente e seu desenvolvimento. Na próxima seção, discutiremos especificamente sobre a construção da identidade docente com base na análise dos relatos.

\section{0 eu professor: análise de movimentos de construção identitária}

A escolha dos trechos para a análise foi pautada na pertinência do que o residente sinaliza em seu texto para a discussão que propomos neste artigo. $\mathrm{Na}$ análise, esses trechos seguem ordem cronológica. Eles foram organizados, para fins de reflexão, como: identificação, feedback, avaliação coletiva e questionamentos. Na época em que participava da RP, o residente era aluno do curso de Letras-Inglês, e suas atividades foram desenvolvidas em uma Escola Cidadã Integral (ECI), no município de 
Bayeux, cidade que compõe a área metropolitana de João Pessoa. A priori, é relevante destacar que o residente experiencia na RP seu primeiro momento de convívio com a docência.

Para fins de análise, também cabe mencionar que a preocupação que o residente textualiza no trecho 1 , a seguir, está relacionada à mudança de preceptor. Em 2019, a escola-campo em que ele estava inserido passou a ser integral. Essa mudança resultou na saída do antigo preceptor e um novo processo seletivo foi realizado. Dessa forma, o trecho descreve seu primeiro contato com a nova preceptora, que será mencionada neste trabalho pelo nome fictício de Joana.

Trecho 1. Identificação

Toda preocupação que tínhamos sobre nosso futuro na RP acabaram quando conhecemos a nova preceptora. Joana é daquelas professoras que eu sempre quis ter nas aulas de inglês: atenciosa, criativa, rápida e super preocupada com a aprendizagem dos alunos.

Nesse trecho, é possível perceber que, já nesse primeiro contato, existe uma conexão do residente com Joana, e essa conexão é evidenciada por meio de expressões que qualificam positivamente a preceptora: atenciosa, criativa, rápida e superpreocupada, ou seja, como o próprio residente afirma, uma professora que ele sempre quis ter durante seus anos como aluno na Educação Básica.

Assim, a identificação do residente com a preceptora é permeada por laços emocionais, afetivos e profissionais criados desde o primeiro dia em que observa e passa a trabalhar com a professora/preceptora. Rememorar o desejo de querer se tornar um professor atencioso e criativo parece vir à tona quando percebe essas características na sua preceptora. Isso pode ser compreendido como o lado afetivo do residente se encontrando com o profissional, que está em formação.

Com base no que ele registra que, como aluno, sempre quis ter uma professora de inglês assim, nos faz perceber, em suas escolhas linguísticodiscursivas, uma propensão a ser um professor com esse perfil, uma vez que há um desejo. "Desejar" em si já é uma força motriz, configura-se como uma demonstração empaticamente propositiva, e perfeitamente pode implicar o desejo de "tornar-se", constituir-se, neste caso específico, vir a ser um professor como sua preceptora. 
Podemos dizer que o primeiro contato com Joana se torna marcante e parece ser responsável por um impacto positivo na construção da sua identidade ao longo de todo o Programa. Consequentemente, sua postura e engajamento são afetados em meio às atividades desenvolvidas a partir daquele momento. Vejamos trechos em que a relação entre o residente e a preceptora vai se consolidando, com parceria e dialogicidade.

\section{Trecho 2. Feedback}

Joana nos chamou e disse que observou a interação da turma e o engajamento deles, e disse que deu para perceber que eles gostaram muito da aula. Esse feedback é muito bom para todos nós.

\section{Trecho 3. Feedback}

Essa professora is an angel. A maneira como ela deu feedback para nós foi tão delicada e tão significativa. Acho ótimo que ela sempre pergunta: mas e você, como você avalia sua performance? Os comentários dela sobre nosso trabalho foram bem legais. Ela falou sobre o uso de tecnologia que é legal, mas às vezes não funciona. Sobre organização de quadro, sobre comportamento nas aulas, e etc. Como eu já venho falando em alguns relatos, estou cada dia mais me surpreendendo com a vivência na escola. Tem sido uma experiência incrivel estar com esse grupo de residentes, com essa preceptora e com alunos tão dedicados. $^{5}$

Os trechos refletem alguns dos diversos diálogos que a preceptora manteve com os residentes sobre questões relacionadas à docência. No segundo trecho, o residente evidencia a relevância dos feedbacks de suas aulas, destacando que esse retorno foi essencial para ele e para os demais residentes (nós). Nesse sentido, o benefício do diálogo estabelecido pela preceptora vai ao encontro da identidade profissional que o(s) residente(s) está(ão) construindo naquele âmbito. Não podemos negar quão importante é o feedback no processo de formação inicial (SABOTA, 2010), sobretudo nesse início do Programa, em que os residentes começariam a planejar suas atividades. A aprovação da preceptora funciona, por assim dizer, como

${ }^{5}$ Grifos nossos. 
motivação para o engajamento de todos os residentes nas atividades propostas. $^{6}$

No terceiro trecho, o residente descreve a relevância de dialogar sobre aspectos da docência. Todo o trecho remete à identidade docente com base na comunicação estabelecida entre preceptora e residentes. Isso nos leva às palavras de Biazi et al (2011), quando as autoras colocam o processo de imersão inicial nas atividades docentes como um espaço essencial e imprescindível para o cultivo do saber partilhado. Além disso, essa imersão é responsável pela construção e pelo desenvolvimento da identidade profissional.

O diálogo que medeia as relações entre o residente e a preceptora, que lança compreensões sobre as possibilidades de um agir, revela ao residente um coletivo possível e necessário para as trocas e para o desenvolvimento profissional (Os comentários dela sobre nosso trabalho foram bem legais. Ela falou sobre o uso de tecnologia que é legal mas às vezes não funciona. Sobre organização de quadro, sobre comportamento nas aulas, e etc.). É um eu que vai se construindo com base nas representações que o outro também tem sobre o trabalho docente. São experiências singulares e distintas ao mesmo tempo, que se completam, se desconstroem e se reconstroem.

Os termos destacados no terceiro trecho demonstram que os "ganhos" acadêmicos e profissionais mencionados pelo residente se dão pela vivência e pelo diálogo com os mais diversos coletivos da escolacampo. A experiência inicial do ser professor atrela-se aos colegas residentes, professores em formação inicial; aos alunos; e à preceptora, responsável pela orientação dele na escola. Conforme Costa e Fontoura (2014) apontam, esses diálogos e vivências, no período inicial da formação, são partes essenciais da socialização profissional, além da imersão no contexto escolar e no desenvolvimento de habilidades e competências que se somam à identidade docente que o residente segue processualmente construindo.

${ }^{6}$ É preciso ressaltar que dez residentes acompanhavam as atividades com Joana. Até o final do Programa, no início do ano 2020, apenas uma residente não finalizou a residência por motivos pessoais. 
É importante mencionar que os feedbacks não eram prescrições que aconteciam em momentos determinados para isso. Pelo contrário, como os trechos nos revelam, eles aconteciam de forma espontânea. Não tinham uma previsão, nem uma norma, revelavam-se como flexíveis e partiam, na maioria das vezes, da preceptora (Joana nos chamou e disse que observou a interação da turma e o engajamento deles, e disse que deu para perceber que eles gostaram muito da aula). Veremos mais sobre isso nos próximos trechos.

\section{Trecho 4. Feedback}

Quando os alunos saíram, Joana veio conversar conosco, nos parabenizando pelas aulas. Ela disse que nas duas turmas, os aluno fizeram "aaaaah, a aula já acabou?" Eles nem fizeram questão de sair da sala. Eu não percebi essas reações, mas confesso que fiquei extremamente emocionado quando a preceptora nos disse isso.

\section{Trecho 5. Feedback}

Quando acabamos essa regência, Joana nos deu parabéns pelas aulas, por termos conseguido dar as cinco aulas seguidas. Ela até brincou que se nós precisássemos de carta de recomendação, era só pedir porque fomos muito bem. É muito emocionante escutar essas coisas. Tô chorando enquanto escrevo todos esses relatos. ${ }^{7}$

A espontaneidade dos feedbacks também pode ser vista nesses trechos. Parte da preceptora evidenciar o engajamento dos alunos nas aulas do residente, além do reconhecimento de sua atividade docente (Ela até brincou que se nós precisássemos de carta de recomendação, era só pedir porque fomos muito bem). Com base nos registros do residente, parece-nos que Joana demonstra entender a importância do feedback positivo para o desenvolvimento do residente.

Ademais, o quarto e o quinto trechos, mais uma vez, evidenciam como a preceptora e o residente conseguiram construir, ao longo do Programa, uma relação de parceria e de confiança. Os momentos de avaliação da preceptora não eram vistos com receio de críticas, mas,

${ }^{7}$ Grifos nossos. 
aparentemente, com o desejo de escuta. As conversas, após as aulas ao final do dia, instituídas no próprio coletivo, como momentos de feedback, também se configuravam como momentos de ânimo para as futuras atividades que estavam planejando. Mais notavelmente, essa parceria era permeada por respeito e por empatia. Esses afetos ficam evidenciados nas emoções textualmente registradas (Tô chorando enquanto escrevo todos esses relatos; confesso que fiquei extremamente emocionado quando a preceptora nos disse isso). Vejamos como, nos trechos seguintes, essa convivência provoca reflexões sobre a atividade docente e sobre a própria formação:

Trecho 6. Avaliação coletiva

Ao final da primeira regência, sentamos com a preceptora e os outros residentes que estavam lá para avaliar a aula e como estávamos nos sentindo em relação à regência. Os comentários da preceptora e dos meninos foram muito construtivos e com certeza nos ajudaram a olhar mais criticamente para a regência do $1^{\circ}$ ano A, que era a próxima.

Dentre as inúmeras características da atividade do trabalho destacamos duas recorrentes nesse trecho. A atividade como interacional e interpessoal (MACHADO, 2007; MACHADO; BRONCKART, 2009). Nesse sexto trecho, percebemos uma avaliação coletiva do trabalho que, nas palavras do residente, se caracteriza como construtiva. Essa avaliação compartilhada sobre o próprio trabalho, no caso do residente, e do trabalho do outro, no caso dos outros residentes e da preceptora, refletem uma instância colaborativa (SABOTA, 2010) - no sentido de discutir coletivamente sobre sua prática -, que é responsável por um olhar crítico para seu agir docente (Os comentários da preceptora e dos meninos foram muito construtivos e com certeza nos ajudaram a olhar mais criticamente para a regência do $I^{\circ}$ ano $A$, que era a próxima.).

De acordo com Fogaça (2011), o trabalho coletivo pode resultar em descobrimentos e aprendizados que poderiam não ocorrer de forma isolada. Nesse caminho, esse trecho e outros já apresentados anteriormente nos mostram a RP como esse espaço de trabalho colaborativo que "ensina" e nos faz descobrir, refletir sobre aspectos da docência que talvez não fossem 
vistos de forma individual em outros espaços formativos, como é o caso do próprio estágio supervisionado. ${ }^{8}$

É possível perceber, com base na análise, essa experiência como algo que transforma e é transformado por meio dos mais variados diálogos entre seus agentes. Esse momento de troca entre residentes e preceptora ainda se caracteriza como trabalho docente amplo em formação, considerando que a atividade docente não se limita à sala de aula, pois a observação e a reflexão sobre sua prática permitem uma reconstituição dela. Nesse sentido, a identidade profissional do residente vai se moldando e se (re)construindo com base em todas essas experiências coletivas construídas nos mais variados espaços oportunizados pelo Programa.

\section{Trecho 7. Questionamentos}

[...] alguns alunos terminaram a atividade e foram escrever no quadro. Eu vi e pedi para que qualquer coisa que eles escrevessem fosse em inglês, e deixei eles continuarem a escrever, afinal não estavam incomodando o restante da turma e já tinham terminado a atividade. Eles inclusive me pediram ajuda para escrever umas frases em inglês sobre o dia dos namorados. Porém, uma pessoa veio comentar comigo sobre como nós tínhamos deixado os alunos depois que terminaram [...] A partir disso que comecei a refletir se o nosso comportamento foi adequado e se tínhamos feito certo, pois, apesar de não termos percebido nada demais, uma pessoa conversou com a gente sobre. Decidi conversar com Joana sobre e perguntar o que ela tinha achado, e ela disse que não tinha nada demais. Ela me disse que nós temos diferentes identidades, e que cada um se comporta na sala de aula de um jeito, o que não é errado. Ela pontuou que

\footnotetext{
${ }^{8}$ Mencionamos o estágio supervisionado porque, em termos práticos, a experiência de estagiar nas escolas tem se configurado como uma vivência até certo ponto solitária com uma finalidade quase exclusivamente voltada para a obtenção de notas, uma vez que o estagiário observa, faz uma regência para fins de avaliação junto à disciplina em que está matriculado. Assim, percebemos nitidamente que essa prática de observação e regência tem sido entendida precipuamente como cumprimento de exigências para aprovação no correspondente componente curricular, na maioria das vezes esvaziada de dialogicidade entre professor regente, professor formador e professor estagiário.
} 
não tinha visto nenhum problema no modo como deixamos a turma nessa aula também, e confesso que isso me aliviou muito.

Como já pontuado previamente, a identidade não é única, estanque, mas fluida (HALL, 2005; BAUMAN, 2005; 2014[2001]) e vai se (re)criando de acordo com as experiências dos sujeitos nas diversas, assimétricas e complexas relações que trava nos variados segmentos sociais por onde transita. No sétimo trecho, Joana parece compartilhar dessa concepção de identidade quando diz ao residente que os professores têm diferentes identidades e que cada um se comporta conforme suas crenças, objetivos e experiências.

Outro aspecto que esse trecho nos mostra é o conflito causado pelo primeiro questionamento (uma pessoa veio comentar comigo sobre como nós tínhamos deixado os alunos depois que terminaram). Como já mencionamos, a atividade docente caracteriza-se como interpessoal e interacional. Nesse sentido, ela sempre engloba outras pessoas. Essas interações comumente podem gerar conflitos que, a nosso ver, e sustentado por Fogaça (2011), podem ser construtivos. Esse trecho permite-nos perceber que o conflito, causado pela fala destacada, se configura como positivo para o desenvolvimento da identidade docente do residente, pois, como bem defende o autor, "entender a natureza de tais confrontos pode ajudar a promover um contexto propício ao crescimento profissional (FOGAÇA, 2011, p. 104).

Nesse caminho, o trecho também nos revela a confiança que o residente deposita na preceptora. Diante de uma situação que gerou questionamentos sobre sua postura como o professor daquela sala de aula, ele se mostra aliviado quando conversa com a preceptora. Esse comportamento pode estar relacionado à maneira como ele vem construindo sua identidade docente com base nos diálogos com Joana. Como evidenciamos na análise do primeiro trecho, houve uma identificação imediata do residente com ela. A confiança depositada nela está diretamente relacionada à sua identidade como professora de Inglês, que o residente descreve como: criativa, rápida, atenciosa $e$ superpreocupada com a aprendizagem dos alunos. ${ }^{9}$ Esse relato também

${ }^{9}$ Parte do primeiro trecho - Identificação. 
evidencia a importância da reflexão sobre as práticas docentes. É sempre uma relação dialógica e dialética, posto que, ao mesmo tempo em que o residente reflete sobre seu próprio agir, Joana também tem a oportunidade de (re)pensar suas ações e seu trabalho docente. O reconhecimento das múltiplas identidades profissionais, em constante re/construção, revela consciência e respeito ao diferente.

Esse olhar para seu próprio agir, oportunizado pelo diálogo entre residente e preceptora, é essencial para a transformação de sua prática. Clot (2010) chama atenção para a observação da própria atividade como uma forma de compreendê-la e, assim, transformá-la. Nesse sentido, essa troca entre os agentes envolvidos no excerto colabora para uma observação e reflexão sobre a própria experiência vivida que lhes permite reconstituir suas práticas docentes e que, indiscutivelmente, afeta suas identidades profissionais.

Trecho 8. Questionamentos

A complicação do dia começa à tarde. U. [outra residente] não pôde ficar na escola. Desse modo, pedi ajuda à professora para as regências nas duas turmas depois do almoço. Esse momento é sempre o mais difícil porque eles voltam do almoço muito cansados. Entretanto, o 2o A foi bem tranquilo. Eles me ouviram, se dedicaram a fazer as atividades e se engajaram. Um grupo ficou quase dormindo no fundo da sala, mas, pacientemente, a professora foi até lá, sentou ao lado delas e começou a ajudá-las com o texto. Foi aí que eu vi toda a turma participando. Foi lindo. ${ }^{10}$

A maneira como o residente vai delineando uma compreensão da prática no seu relato salienta as várias dinâmicas na maneira como entendemos nosso agir profissional. Em apenas um turno, os diversos sentidos construídos para o fazer (complicação do dia; sempre o mais difícil, bem tranquilo, foi lindo) ratifica a fluidez (BAUMAN, 2014[2001]) das ações e, consequentemente, das nossas percepções do vivido. Do complicado ao lindo, uma gama de experiências e emoções que, certamente, não passam incólumes no processo de construção identitária.

${ }^{10}$ Grifos nossos. 
Acreditamos que o diálogo direto e constante entre preceptora e residente possibilitou a reflexão acerca da atividade de ambos os agentes, além de uma maior aproximação do licenciando com o campo de sua futura prática. Os trechos sinalizam o diálogo entre residente e a preceptora como um espaço de conexão marcada substancialmente por questões afetivas e profissionais. Baseado no que a preceptora lhe oferece como estímulo para a reflexão sobre o contexto e a prática docente, o residente resgata memórias que fazem parte de sua identidade como aluno de Língua Inglesa e as reconstrói como professor em formação, vendo no papel assumido pela preceptora uma oportunidade de partilha sobre saberes docentes.

Os segundo, terceiro, quarto, quinto e sexto trechos também refletem o feedback como forma de crescimento e reflexão pessoal e profissional, pois há uma identificação e uma aproximação que o residente estabelece com a preceptora. Assim, essa identificação gera confiança e percepção de identidades profissionais diversas e possíveis. Esses movimentos, nomeados neste texto de identificação, feedback, avaliação coletiva e questionamentos, permitem a observação de uma identidade docente em constante (re)construção.

Costa e Fontoura (2015, p. 172) descrevem experiências docentes como as vivenciadas pelo residente como algo que "te coloca dentro da escola de outro jeito. Você tem tempo para se adaptar, conhecer o ambiente, se aproximar das turmas, dos colegas, criar vínculo com a escola'. É isto que se evidencia na análise: a criação de vínculos e crescimento profissional com base nas relações sociais construídas no contexto da escola. $\mathrm{O}$ estabelecimento dessas relações nos dá margem para compreendermos esse tornar-se docente como um (re)fazer-se fluido que, em muitas situações, requer descontinuidades para que haja a continuidade nos processos identitários relacionados à docência.

\section{Algumas considerações}

Embora seja um Programa bastante recente, a RP tem se configurado como espaço complementar que contribui consideravelmente para a formação inicial dos agentes envolvidos. Como discutimos em seções anteriores, muitos licenciandos experienciam na RP o primeiro contato com a docência. Além disso, os participantes conseguem mergulhar 
com profundidade na cultura escolar, não estando limitados apenas às quatro paredes de uma sala de aula. É possível entender melhor o funcionamento de uma escola, desde a secretaria, a coordenação até a biblioteca e a cantina. A imersão é impactante e afeta, sobremaneira, a identidade profissional dos residentes. Nesse processo, podemos constatar a relação constitutiva que cada um tem com a escola, com a sala de aula. Da mesma forma, esse contato pode se revelar, por vezes, frustrante.

Conforme ficou demonstrado durante a análise, é possível refletir mais efetivamente sobre o ensino e sobre a identidade profissional. $\mathrm{O}$ aluno licenciando pôde perceber, nos textos de registro das atividades desenvolvidas entre preceptora e residente, como são profícuas as relações estabelecidas, contribuindo significativamente para a criação de uma identidade de professor de Língua Inglesa. Finalmente, as vivências dialógicas de uma rotina compartilhada entre o residente e a preceptora contribuíram para uma construção identitária que, a nosso ver, se caracterizou como crítica e consciente. Os diálogos, alimentados por ambos, de uma maneira respeitosa e producente, possibilitaram não apenas reflexões acerca da atividade profissional, mas, primordialmente, dos movimentos e das surpresas de uma identidade profissional que se constrói com outro(s).

\section{Referências}

ARAÚJO, Maria Dalvaneide de Oliveira; BARROS, Gleize Cristina França de; BARROS, Marcos Alexandre de Melo. A construção da identidade docente do licenciado de Ciências Biológicas em início de carreira. RIS - Revista Insignare Scientia, v. 1, n. 2., mai./ago. 2018.

BAUMAN, Zygmunt. Identidade: entrevista a Benedetto Vecchi. Rio de Janeiro: Zahar, 2005.

BAUMAN, Zygmunt. Modernidade líquida. Tradução: Plínio Dentzien. Rio de Janeiro: Zahar, 2014 [2001].

BIAZI, Terezinha Marcondes Diniz; GIMENEZ, Telma; STUTZ, Lidia. O papel da observação de aulas durante o estágio supervisionado de Inglês. Revista Sigmum: Estudos da Linguagem, v. 14, n. 1, p. 57-78, 2011. 
Os diálogos entre preceptor e residente...

BRASIL. Edital Capes 06/2018, que dispõe sobre a Residência Pedagógica. 2018. Disponível em: <https://www.capes.gov.br/images/stories/download/editais/01032018-Edital-62018-Residencia-pedagogica.pdf> Acesso em: 10 maio 2020.

BRASIL. Base Nacional Comum Curricular. Brasília: MEC, 2017.

CLOT, Yves. Clínica da atividade e psicopatologia do trabalho. In: CLOT, Yves. Trabalho e poder de agir, 2010. p. 99-116.

COSTA, Luciana Laureano; FONTOURA, Helena Amaral. Residência Pedagógica: criando caminhos para o desenvolvimento profissional docente. Revista@ambienteeducação, São Paulo,v. 9, n. 2, 2015.

FOGAÇA, Francisco Carlos. Conflito e desenvolvimento: duas faces da mesma moeda. In: CRISTOVÃO, V. L. L. Atividade docente e desenvolvimento. Campinas: Pontes Editora, 2011.p. 91-105.

GARCIA, Maria M. A.; HYPOLITO, Alvaro M.; VIEIRA, Jarbas S. As identidades docentes como fabricação da docência. Revista Educação e Pesquisa, São Paulo, v. 31, n. 1, p. 45-56, jan./mar. 2005.

GERHARDT, Tatiana Engel; SILVEIRA, Denise Tolfo. Métodos de pesquisa. Universidade Aberta do Brasil - UAB/UFRGS; Curso de Graduação Tecnológica Planejamento e Gestão para o Desenvolvimento Rural da SeaD/UFRGS. - Porto Alegre: Editora da UFRGS, 2009.

GONÇALVES, Kelry Alves. Identidade docente nos artigos da Anped 2010/2014. Rebes - Revista Brasileira de Ensino Superior, 2(3), p. 5-17, jul.-set. 2016.

HALL, Stuart. A identidade cultural na pós-modernidade. 10. ed. Rio de Janeiro: DP\&A, 2005.

IZA, Dijnane Fernanda Vedovatto; BENITES, Larissa Cerignoni; SANCHES NETO, Luiz; CYRINO, Marina; ANANIAS, Elisangela Venâncio; ARNOSTI, Rebeca Possobom; Identidade docente: as várias faces da constituição do ser professor. Revista Eletrônica de Educação, v. 8, n. 2, p. 273-292, 2014. Disponível em: < http://www.reveduc.ufscar.br/index.php/reveduc/article/view/978>. Acesso em: 10 maio 2020. 
MACHADO, Anna Rachel. Por uma concepção ampliada do trabalho do professor. In: BRONCKART, Jean-Paul; GUIMARÃES, Ana Maria de Mattos et al. O interacionismo sociodiscursivo: questões epistemológicas e metodológicas. São Paulo: Mercado de Letras, 2007. p. 77-97.

MACHADO, Anna Raquel; BRONCKART, Jean Paul. Reconfigurações do trabalho do professor construídas nos e pelos textos: a perspectiva metodológica do grupo ALTER-LAEL In: CRISTOVÃO, Vera Lúcia Lopes; ABREUTARDELLLI, Lília Santos (Org.) Linguagem e educação: o trabalho do professor em uma nova perspectiva. São Paulo: Mercado de Letras, 2009.

MEDRADO, Betânia Passos; COSTA, Walison Paulino de Araújo. O Programa de Residência Pedagógica: refletindo sobre a formação dos coletivos de trabalho. In: GUIMARÃES, Ana Maria; CARNIN, Anderson; LOUSADA, Eliane Gouvêa (Org.). $O$ interacionismo sociodiscursivo em foco: reflexões sobre uma teoria em contínua construção e uma práxis em movimento. 1. ed. Araraquara: Letraria, 2020. v. 1, p. 141-162.

MEDRADO, Betânia Passos; VELOSO- LEITAO, Liane. Por entre paisagens líquidas: a construção identitária de professores de inglês no contexto de cursos de idiomas. In: OLIVEIRA, Luciani Salcedo de; BOER, Raphael Albuquerque de (Org.). Professores(as) de línguas em uma perspectiva crítica: discursos, linguagens e identidades. 1. ed. Campinas: Pontes, 2018. v. 1, p. 43-68.

MUNIZ-OLIVEIRA, Siderlene. Uma interpretação discursiva sobre o real da atividade docente no ensino superior: dificuldades e super-ações. D.E.L.T.A., 32, 1, p. 75-97, 2016.

NÓVOA, António. Professores: imagens do futuro presente. Lisboa: Educa, 2009.

REICHMANN, Carla Lynn. (Org.). Diários reflexivos de professores de línguas: ensinar, escrever, refazer(-se). 1. ed. Campinas: Pontes Editora, 2013. v. 1, p. 7192.

REICHMANN, Carla Lynn. Letras e letramentos: escrita situada, identidade e trabalho docente no estágio supervisionado. São Paulo: Mercado de Letras, 2015.

SABOTA, Barbra. Entre o querer e o fazer: considerações sobre a formação universitária reflexiva de professores de línguas. Revista Horizontes de Linguística Aplicada, v. 9, n. 1, p. 65-79, 2010. 
Os diálogos entre preceptor e residente...

TARDIF, Maurice. Saberes docentes e formação profissional. Petrópolis: Vozes, 2002.

Recebido em: 29/07/2020

Aceito em: 12/11/2020

Title: The dialogues between preceptor and resident in the context of pedagogical residence: reflections in favor of a construction of teacher identity 